\title{
STRUKTUR KOMUNITAS MESOFAUNA TANAH PEROMBAK BAHAN ORGANIK PADA VEGETASI KOPI DAN KAKAO
}

\author{
Kristina Erniyani $^{1}$, Sri Wahyuni ${ }^{2}$ dan Yustina M.S.W. Pu' ${ }^{2}$ \\ ${ }^{1}$ Badan Ketahanan Pangan Kabupaten Ende, ${ }^{2}$ Program Studi Agroteknologi Fakultas \\ Pertanian Universitas Flores
}

Kristinaerni@yahoo.co.id

\begin{abstract}
Alteration Of Soil The Structure And Ecosystem By Organic Matter In Coffee And Cocoa Plantations

The use of inorganic fertilizers and pesticides can change the agro ecosystem gradually. These changes may result in the decrease of diversity of soil organisms. These organisms are very important in the decomposition process of reforming the organic matter into compounds that are readily absorbed by plants. Other changes include a change in the soil structure whuch will affect the soil chemical and physical characteristic and ultimately affect the soil productivity leading to decreased agricultural products. The return of the remains from harvest, litter and crop residues from coffee and cocoa crops to soil will provide energy for soil organisms and it will help maintain the soil environment that supports the life of other organisms. This research aimed at identifing the composition and diversity of mesofauna formed by decomposed organic matter in cocoa and coffee plantations.

Soil sampling was conducted on coffee and cocoa plantations in the Onelako village of Ndona District. Soil sampling was conducted on September 2010. Soil sampling used Neuman method of $0-15 \mathrm{~cm}$ and $16-30 \mathrm{~cm}$ depth. Each soil sample was taken to the laboratory. The separation of mesofauna from soil used Berlese-tullgran method that had been modified for 4 days. The separated Mesofauna was identified under the light microscope.

The result of this research showed that the highest composition of mesofauna decomposer of organic matter in cocoa and coffee vegetation is Collembola. Collembola are very tolerant to acidic soil conditions and they are dominant in the soil and surface habitats that contain lots of litter. Collembola are microartopoda that have large distribution both in quantity and diversity. The highest diversity of mesofauna on coffee vegetation are 1.525 and on cocoa vegetation are 1.273. It was also noted that the at a depth of $0-15 \mathrm{~cm}$ there was a higher concentration of mesofauna in the coffee vegetation area, which was about 7.3960 , while in the cocoa vegetation there were 3.6376. The high level of the diversity index caused an increase in decomposition and therefore better soil fertility.
\end{abstract}

Keywords: mesofauna, vegetation coffee, vegetation cocoa 


\section{PENDAHULUAN}

Penggunaan pupuk dan pestisida anorganik perlahan-lahan akan mengubah agroekosistem. Perubahan ini berakibat pada menurunnya keragaman organisme tanah atau biologi tanah, perubahan sifat kimia dan fisik tanah yang pada akhirnya berpengaruh terhadap produktivitas tanah dan penurunan produksi pertanian. Santosa (2007) menjelaskan pengelolaan lahan yang tidak memenuhi kaidah-kaidah yang benar akan menyebabkan penurunan kelimpahan dan keragaman fauna tanah. Dalam waktu yang panjang akan berakibat pada terganggunya siklus hara alami dalam agroekosistem, menurunnya kualitas dan produktivitas lahan.

Serasah, limbah buah (kulit buah dari kopi dan kakao) dan sisa tanaman lainnya pada kebun kakao maupun kopi dapat yang dikembalikan ke tanah menjadi salah satu sumber bahan organik sekaligus menyediakan energi bagi organisme tanah. Serasah dan limbah tanaman ini terurai melalui proses dekomposisi secara alami. Proses dekomposisi ini akan terjadi jika ada keterlibatan organisme tanah. Suwondo (2002) menjelaskan bila indeks keragaman fauna tanah besar (> 3) berarti tingkat dekomposisi yang terjadi tinggi sebaliknya tingkat dekomposisi akan rendah jika indeks keragaman fauna tanah rendah $(<1)$. Indeks keragaman tinggi berarti tingkat kesuburan tanah tinggi. Oleh karena itu perlu dilakukan pengkajian tentang keragaman fauna tanah dalam berbagai jenis bahan pupuk organik.
Berdasarkan ukuran tubuh, fauna tanah dikelompokan menjadi 1) mikrofauna adalah kelompok fauna tanah dengan ukuran panjang $<0.15$ $\mathrm{mm}$ seperti bakteri, nematoda; 2) mesofauna adalah kelompok fauna tanah dengan ukuran panjang 0.16-10.4 mm seperti collembola, acarina, protura; 3) makrofauna adalah kelompok fauna tanah dengan ukuran panjang > 10.5 (Suhardjono dan Adisoemarto, 1997 dalam Suwondo, 2002).

Dari sejumlah fauna yang berperan dalam proses penguraian serasah terdapat satu kelompok fauna yang digolongkan sebagai mesofauna tanah. Mesofauna tanah merupakan fauna tanah dengan ukuran tubuhnya 0.16 $10.4 \mathrm{~mm}$. Mesofauna berperan sebagai perombak awal bahan makanan, serasah, dan bahan organik lainnya (seperti kayu dan akar) menjadi fragmen berukuran kecil yang siap untuk dirombak oleh mikroba tanah lainnya. Dalam metabolismenya, mesofauna mengeluarkan faeces yang mengandung berbagai hara dalam bentuk tersedia bagi tanaman dan kehidupan lainya yang ada dalam tanah.

Dengan demikian mesofauna tanah merupakan salah satu komponen dari ekosistem tanah. Kehidupan mesofauna tanah sangat tergantung pada habitatnya, karena keberadaan dan kepadatan populasi suatu jenis fauna tanah di suatu daerah sangat ditentukan oleh faktor lingkungan biotik dan abiotik daerah tersebut.

Lingkungan biotik meliputi vegetasi di permukaan tanah dan organisme lainya. Selain berfungsi sebagai penghasil serasah sekaligus 
sebagai penutup tanah. Sedangkan lingkungan abiotik meliputi suhu dan kelembaban tanah, sifat kimia tanah seperti $\mathrm{pH}$, serta sifat fisik tanah. Suhu tanah dipengaruhi oleh suhu udara. Suhu tanah akan lebih rendah dari suhu udara. Sifat fisik tanah akan mempengaruhi porositas udara dalam tanah.

Keadaan iklim daerah dan berbagai tanaman yang tumbuh pada tanahnya serta berlimpahnya mikroorganisme yang mendiami suatu daerah akan mempengaruhi keanekaragaman relatif populasi mikroorganisme. Faktor-faktor lain yang mempunyai pengaruh terhadap keanekaragaman relatif populasi mikroorganisme adalah reaksi yang berlangsung di dalam tanah, kadar kelembaban.

Sebagaimana diketahui, terdapat berbagai jenis vegetasi yang tumbuh dipermukaan tanah. Di antaranya kopi dan kakao.

Seperti halnya dengan vegetasi yang lain, kopi dan kakao juga banyak menghasilkan serasah dan sisa tanaman yang dapat dimanfaatkan sebagai sumber hara bagi tanaman. Terhadap serasah dan sisa-sisa tanaman, mesofauna berperan aktif dalam proses dekomposisi.

Penelitian ini bertujuan mengetahui komposisi dan keragaman mesofauna perombak bahan organik pada vegetasi kakao dan kopi.

\section{METODE}

Percobaan ini dilakukan di kebun kakao dan kebun kopi milik petani di
Kelurahan Onelako Kecamatan Ndona Kabupaten Ende. Penelitian dilaksanakan pada bulan September Oktober 2010. Identifikasi fauna tanah dilakukan di Laboratorium Fakultas Pertanian Universitas Flores dan analisis tanah dilakukan di Laboratorium Tanah Fakultas Pertanian Universitas Udayana.

Pengambilan sampel tanah dengan metode Neuman (Anwar, 2007). Setiap lokasi diambil 5 sample. Pemisahan mesofauna tanah dari tanah dengan metode Dinamik menggunakan BarleseTullgren. Pengamatan dilakukan terhadap jenis mesofauna yang ditemukan, kepadatan relatif mesofauna, indeks keragaman ShannonWiener dan dominansi fauna tanah. Data pendukung antara lain, suhu permukaan tanah dan suhu tanah, $\mathrm{pH}$ tanah, bahan organik tanah, C-organik, $\mathrm{N}$ total tanah, $\mathrm{P}$ tersedia dan $\mathrm{K}$ tersedia.

\section{HASIL DAN PEMBAHASAN}

\section{Faktor Fisik dan Kimia}

Pengukuran faktor fisik dan kimia pada area penelitian disajikan pada Tabel 1. Hasil pengukuran menunjukkan suhu tanah berkisar antara 21,17 sampai $22,78{ }^{\circ} \mathrm{C}$. Suhu tanah lebih tinggi pada vegetasi kakao baik pada kedalaman $0-15 \mathrm{~cm}\left(22,78{ }^{\circ} \mathrm{C}\right)$ dan pada kedalaman $16-30 \mathrm{~cm}\left(22,13{ }^{\circ} \mathrm{C}\right)$. Suhu mempengaruhi aktivitas mikroorganisme dalam tanah. Aktivitas mikroorganisme tersebut berfungsi sebagai pemicu proses fisik dalam pembentukan liat dari mineral - mineral bahan induk tanah dengan mekanisme identik proses pelapukan batuan serta 
biomassa yang menjadi sumber energi bagi organisme tanah sehingga menentukan keragaman hayati yang aktif dan menunjang kesempurnaan proses dekomposisi tanah hingga kemineralisasi (Hanafiah, 2005). Wallwork (1970) menyatakan besarnya perubahan gelombang suhu pada lapisan tanah berhubungan dengan jumlah radiasi sinar matahari yang jatuh pada permukaan tanah. Besarnya radiasi yang terintersepsi sebelum sampai pada permukaan tanah, tergantung pada vegetasi yang ada di atas permukaannya.

Hasil pengukuran $\mathrm{pH}$ tanah menunjukkan kondisi tanah pada area percobaan agak masam, dengan kisaran $6,00-6,68$. Tingkat kemasaman tanah sangat mempengaruhi kehidupan mesofauna tanah. Tanah dengan kondisi sangat masam menjadi faktor pembatas pertumbuhan dan perkembangan mesofauna (Suwondo, 2002). Suin (1997) menyebutkan bahwa ada fauna tanah yang hidup pada tanah yang $\mathrm{pH}$ nya asam dan ada pula yang senang hidup pada tanah yang memiliki $\mathrm{pH}$ basa. Jenis Collembola yang memilih hidup pada tanah yang asam disebut dengan Collembola golongan asidofil, yang memilih hidup pada tanah yang basa disebut dengan Collembola golongan kalsinofil, sedangkan yang dapat hidup pada tanah asam dan basa disebut Collembola golongan indifferen.

Hasil pengukuran kadar air kering udara menunjukkan lebih tinggi pada area dengan vegetasi kopi dibandingkan vegetasi kakao. Data ini menunjukkan bahwa tanah yang ada di area vegetasi kopi mempunyai daya pegang air lebih tinggi.

Tabel 1. Sifat fisik dan kimia tanah pada area percobaan

\begin{tabular}{lcccc}
\hline \multicolumn{1}{c}{ Parameter fisik } & \multicolumn{2}{c}{ Kedalaman } & $0-15 \mathrm{~cm}$ & \multicolumn{2}{c}{ Kedalaman } & $16-30 \mathrm{~cm}$ \\
\cline { 2 - 5 } & Vegetasi & Vegetasi & Vegetasi & Vegetasi kopi \\
& Kakao & kopi & Kakao & \\
\hline Suhu tanah $\left({ }^{\circ} \mathrm{C}\right)$ & 22,78 & 21,54 & 22,13 & 21,17 \\
Ph & 6,35 & 6,80 & 6,00 & 6,23 \\
Kadar air KU (\%) & 8,49 & 10,10 & 9,74 & 12,16 \\
Bahan organik & 3,6376 & 7,3960 & 7,3787 & 7,5339 \\
C-organik & $2,11(\mathrm{~S})$ & $4,29(\mathrm{~T})$ & $4,28(\mathrm{~T})$ & $4,37(\mathrm{~T})$ \\
N-total & $0,12(\mathrm{R})$ & $0,17(\mathrm{R})$ & $0,11(\mathrm{R})$ & $0,13(\mathrm{R})$ \\
Tekstur tanah & Lempung & Lempung & Lempung liat & Lempung liat \\
& berpasir & & berpasir & berpasir \\
\hline
\end{tabular}

Hasil penelitian menunjukkan pada area vegetasi kakao, permukaan tanah terbuka, tidak terdapat serasah dan rumput sebagai penutup tanah. Pada area vegetasi kopi, permukaan tanah tertutup rumput dan serasah. Rumput dan serasah merupakan sumber biomasa yang kemudian akan dirombak menjadi senyawa yang tersedia bagi tanaman. Proses perombakan tersebut akan dibantu oleh organisme tanah. Hasil dekomposisi serasah yang berasal dari 
tumbuhan atau hewan yang sudah mati akan membentuk bahan organik. Data analisis laboratorium menunjukkan kadar bahan organik tanah dengan kedalaman 0-15 cm pada vegetasi kopi lebih tinggi sebesar 103,32 \% dari vegetasi kakao. Pada kedalaman 16-30 $\mathrm{cm}$ pada vegetasi kopi sebesar 2,10\% dari vegetasi kakao.

\section{Struktur dan Komposisi Mesofauna Tanah}

Tabel 2 menunjukkan komposisi mesofauna yang ditemukan berada pada kedalaman 0-15 cm, sedangkan pada 16-30 cm tidak ditemukan. Dari tabel tersebut didapat hanya terdapat 17 spesies yang ditemukan di area dengan vegetasi kakao dan 34 spesies ditemukan di area dengan vegetasi kopi. Perbedaan jumlah spesies mesofauna antara area vegetasi kakao dan vegetasi kopi diduga disebabkan oleh adanya tanggapan yang berbeda terhadap kondisi mikroklimat lingkungan. Wallwork (1970) menjelaskan mikroartopoda tanah mempunyai toleransi yang berbeda terhadap faktor fisikokimia lingkungan. Faktor fisikokimia yang mempengaruhi fauna antara lain suhu, kadar air, kandungan bahan organik dan $\mathrm{pH}$ tanah.

Selain itu perbedaan terjadi karena perbedaan materi organik (serasah dan sisa tanaman) yang ada di ke dua area tersebut. Hal ini seperti yang ditunjuk pada Tabel 1. dimana C-organik dan bahan organik pada kedalaman $0-15 \mathrm{~cm}$ lebih tinggi pada area vegetasi kopi daripada vegetasi kakao. Suharjo et al (1993) dalam Sugiyarto (2001) mengemukakan bahwa bahan organik berperan sebagai sumber energi bagi kebanyakan biota tanah sehingga semakin banyak dan beragam bahan organik yang tersedia, maka semakin banyak dan keragaman pula biota tanah.

Tabel 2. Jenis Mesofauna yang ditemukan

\begin{tabular}{llclc}
\hline $\begin{array}{c}\text { Kedalaman } \\
\text { tanah }\end{array}$ & \multicolumn{2}{c}{ Komunitas Kakao } & \multicolumn{2}{c}{ Komunitas Kopi } \\
\hline \multirow{2}{*}{$15 \mathrm{~cm}$} & \multicolumn{1}{c}{ Spesies } & Jumlah & \multicolumn{1}{c}{ Spesies } & Jumlah \\
& Ordo Collembola & & Ordo Collembola & \\
& Dirictoma daurdensi & 3 & D. daurdensi & 8 \\
& Dirictoma ornata & 3 & D. ornata & 5 \\
& Folsomia sp. & 8 & Folsomia sp. & 12 \\
& - & & Diplura. & 4 \\
& Acarina & 3 & Acarina & 5 \\
\hline Jumlah & - & 17 & - & 34 \\
\hline $30 \mathrm{~cm}$ & - & - & - & - \\
\hline
\end{tabular}

Jenis collembola menempati proporsi yang tertinggi baik pada area vegetasi kopi maupun kakao (Tabel 2). Hal ini karena collembola sangat toleran 
kondisi tanah masam. Russell (1988) menyebutkan bahwa collembola merupakan mikroartopoda yang melimpah baik jumlah maupun keanekaragamannya serta memiliki agihan yang luas. Takeda (1981) dalam (Suwondo, 2002), collembola juga merupakan mikroartopoda yang dominan pada habitat tanah dan menyukai habitat permukaan tanah yang banyak mengandung serasah. Diplura dan Acarina ditemukan dalam jumlah sedikit.

Keragaman jenis mesofauna pada tanah menunjukkan bahwa vegetasi yang ada diatas permukaan tanah juga memiliki pengaruh terhadap keberadaan jenis - jenis mesofauna tanah tertentu. Hal tersebut disebabkan oleh setiap vegetasi memiliki ciri spesifik yang juga dimanfaatkan oleh mesofauna tanah dalam rangkaian alur energinya dan secara tidak langsung memberikan pengaruh terhadap sifat biologi tanah. Selain keragaman jenis, kerapatan populasi juga menggambarkan aktivitas mesofauna tanah dalam habitatnya berlangsung dengan baik. Berikut data kerapatan, Indeks keragaman dan dominansi jenis mesofauna tanah yang ada pada vegetasi kopi dan kakao.

Tabel 3. Kerapatan, Indeks Keragaman dan Dominansi

\begin{tabular}{|c|c|c|c|c|c|c|c|}
\hline \multirow{2}{*}{$\begin{array}{c}\text { Ke- } \\
\text { dalaman }\end{array}$} & \multirow{2}{*}{ Mesofauna } & \multicolumn{3}{|c|}{ Komunitas kakao } & \multicolumn{3}{|c|}{ Komunitas kopi } \\
\hline & & KR & $\mathrm{H}^{\prime}$ & I & KR (\%) & $\mathrm{H}^{\prime}$ & I \\
\hline \multirow[t]{5}{*}{$15 \mathrm{~cm}$} & D. daurdensi & 17,65 & 0,306 & 0,031 & 23,53 & 0,341 & 0,055 \\
\hline & D. ornate & 17,65 & 0,306 & 0,031 & 14,71 & 0,282 & 0,022 \\
\hline & Folosomia sp. & 47,06 & 0,355 & 0,222 & 35,29 & 0,368 & 0,125 \\
\hline & Formicidae sp. & 0 & 0 & 0 & 11,77 & 0,252 & 0,014 \\
\hline & Acarina & 17,65 & 0,306 & 0,031 & 14,71 & 0,282 & 0,022 \\
\hline Jumlah & & 100 & 1,273 & 0,315 & 100 & 1,525 & 0,238 \\
\hline $30 \mathrm{~cm}$ & - & - & - & - & - & - & - \\
\hline mlah & & 0 & 0 & 0 & 0 & 0 & 0 \\
\hline
\end{tabular}

Keterangan KR : Kerapatan Relatif

\section{H' : Indeks Keragaman Shannon-Wiener}

I : indeks dominansi

Hasil penelitian menunjukkan bahwa indeks keragaman fauna pada vegetasi kakao dan vegetasi kopi berdasarkan indeks Shannon-Wiener yaitu sebesar 1,273 dan 1,525. Nilai indeks keragaman fauna pada area vegetasi kakao tergolong rendah sehingga proses dekomposisi berjalan lambat. Pada area vegetasi kopi tergolong sedang dengan demikian proses dekomposisi lebih cepat dibandingkan dekomposisi yang terjadi pada area vegetasi kakao. Pernyataan ini dibuktikan dengan bahan organik yang terdapat pada area vegetasi kopi lebih tinggi dibandingkan vegetasi kakao pada kedalaman 0-15 cm yaitu 7,3960 sedangkan pada vegetasi kakao sebesar 
3,6376. Suwondo (2002) menjelaskan bahwa semakin tinggi indeks keragaman semakin tinggi tingkat dekomposisi sehingga kesuburan tanah semakin baik.

Indeks dominansi semakin kecil menunjukkan komposisi fauna dalam tanah semakin seimbang. Nilai indeks dominan mendekati 0,5 menunjukkan populasi masing-masing fauna dalam keadaan seimbang (Magurran, 1988 dalam Rahmawaty, 2004). Hasil penelitian menunjukkan indeks dominansi baik pada vegetasi kopi maupun kakao menunjukkan nilai mendekai 0,5 (Tabel 3). Hal ini menunjukkan bahwa populasi mesofauna pada masing-masing vegetasi dalam keadaan seimbang.

\section{SIMPULAN}

Dari hasil penelitian dapat disimpulkan bahwa

1. Komposisi mesofauna perombak bahan organik tertinggi pada vegetasi kakao dan vegetasi kopi adalah Collembola.

2. Keragaman mesofauna tertinggi pada vegetasi kopi sebesar 1,525 daripada vegetasi kakao sebesar 1,273 .

\section{UCAPAN TERIMAKASIH}

Pada kesempatan ini penulis ingin mengucapkan terimakasih yang sebesar - besarnya kepada DIKTI cq. DP2M yang telah membiayai penelitian ini, Dinas BKP3 atas perijinannya, pihak yayasan Universitas Flores dan Fakultas Pertanian Universitas Flores atas kerjasamanya.

\section{DAFTAR PUSTAKA}

Anwar, E. K. 2007. Pengambilam Contoh Untuk Penelitian Fauna Tanah. Dalam : Metode Analisis Biologi Tanah. Editor. Rasti Saraswati, Edi Husen, R.D.M Simanungkalit. Balai Besar Litbang Sumberdaya Lahan Pertanian. Badan Penelitian dan Pengembanga Petanian. Departemen Pertanian. 2007

Rahmawati. 2004. Studi Keanekaragaman Mesofauna

Tanah Di Kawasan Hutan Wisata Alam Sibolangit. Jurusan Kehutanan Program Studi Manajemen Hutan Fakultas Pertanian Universitas Sumatera Utara.

Russell, E.W. 1978. Soil Condition and Plant Growth. London: English Language Book Society.

Santosa, E. 2007. Analisis Kelimpahan dan Keragaman Fauna Tanah. Editor. Rasti Saraswati, Edi Husen, R.D.M Simanungkalit. Balai Besar Litbang Sumberdaya Lahan Pertanian. Badan Penelitian dan Pengembanga Petanian. Departemen Pertanian. 2007

Suin, N.M. 2006. Ekologi Hewan Tanah. PT Bumi Aksara. Jakarta

Suhardjono, Y. R. 2000. Collembola Tanah : Peran dan Pengelolaannya. Lokakarya Sehari Peran Taksonomi dalam 
AGRICA, VOL.3 NO 1 (2010)

Pemanfaatan dan Pelestarian

Keanekaragaman Hayati di

Indonesia. Depok. Hal : 3.

Suhardjono, Y. R. dan Adisoemarto. 1997. Arthopoda Tanah : Artinya Bagi Tanah Makalah pada Kongres dan Simposium Entomologi V, Bandung $24-26$ Juni 1997. Hal : 10.

Suwondo. 2002. Komposisi dan keanekaragaman Mikroorthropoda Tanah sebagai Bioindikator Karakteristik Biologi pada Tanah Gambut. Program Studi Biologi PMIPA. FKIP Universitas Riau.

Wallwork, J. A. 1970. Ecology of Soil Animals. Mc Graw Hill. London. 283 p. 